\title{
Commercial Dispute Resolution: Unlocking Economic Potential Through Lighthouse Projects
}

\author{
Andreas Baumgartner*
}

\begin{abstract}
This chapter positions commercial dispute resolution as a major enabler of economic development. Going one step further, it argues that commercial dispute resolution also makes for good 'lighthouse' judicial reform projects, due to its focused scope and the quick impact potential in an area where competition between countries requires urgent action. Success requires a comprehensive approach around five building blocks: the legal basis; organisational and physical setup; people excellence; communications; and overall strategy and change management. In its second half, the chapter moves from today to setting out four hypotheses for the future: Firstly, courts of the future will be a service rather than a location, with courtrooms of the future being virtual and customer centric providers capturing the market. Second, commercial dispute resolution will become far more differentiated, as well as competitive on the international stage. Third, private sector solutions will complement and compete with state-offered or endorsed solutions. Fourth, artificial intelligence is about to change the face and nature of dispute resolution fundamentally. Each of those trends offers ample opportunities to unlock economic potential. The chapter concludes by pointing out how international organizations can contribute.
\end{abstract} Major Enabler of Economic Development

As countries are competing ever more vigorously for economic development, ${ }^{1}$ market size and potential, institutional and regulatory quality, openness to trade, infrastructure quality, economic and political stability and labour

\footnotetext{
* Andreas Baumgartner, co-founder and the current CEO of The Metis Institute, a.baumgartner@themetisinstitute.org.

1 Barros and Cabral 2000, 360-71; Vuksic 2015; Gonzalez, 26 October 2017.
}

(C) ASIAN INFRASTRUCTURE INVESTMENT BANK (AIIB), 2019 | DOI:10.1163/9789004407411_013

This is an open access chapter distributed under the terms of the CC-BY-NC 4.0 License. 
quality as well as cost are still paramount. ${ }^{2}$ However, there is another key factor of economic (but also social and political) development which is often overlooked, even though it features, for example, in the 'Ease of Doing Business' index of The World Bank: 'The enforcing contracts indicator measures the time and cost for resolving a commercial dispute through a local first-instance court, and the quality of judicial processes index, evaluating whether each economy has adopted a series of good practices that promote quality and efficiency in the court system. ${ }^{3}$

The argument runs that better dispute resolution contributes to a better business climate and, as a consequence, to the attractiveness as a destination for foreign direct investment. ${ }^{4}$ As has been noted, "economic development requires not only that there be predictable and fair rules to govern business activities but that these rules are actually enforced", ${ }^{5}$ for which commercial dispute resolution is an important factor. Or, "Simply emphasizing the significance of property rights is not sufficient. [...] Property rights must be readily enforceable and credible to have the desired effect". 6

Some literature even goes so far to claim that "judicial efficiency explains more of the pattern of [Foreign Direct Investment] FDI than the combined skilled labour and capital endowment",7 or puts institutions, explicitly including courts, at the same level of importance as the three major factors in classical economic theory, money, people, and resources. ${ }^{8}$ Others are more cautious, emphasizing the difficulties of operationalizing the impact of rule of law on the economy for empirical research. ${ }^{9}$ However, even the more cautious authors concede a statistically significant effect of the quality of trading parties' domestic legal institutions on trade. ${ }^{10}$ And - even though with a number of caveats regarding the sample size and the need to resort to proxies to measure reform efforts-econometric analysis appears to support the hypothesis that judicial reforms may enhance entrepreneurial activity and foreign direct investment. ${ }^{11}$

\footnotetext{
Hornberger 2011, 2.

World Bank, 'Enforcing Contracts Methodology'.

McConnaughy 2013, 14; in the article with respect to dispute resolution by arbitration.

Fry 2011, 390.

Cross 2002, 1743 .

Bellani 2014, with further literature references.

Weisbrot 2003, 252.

Cross 2002, 1768 .

For example Fry 2011, 391.

Lorenzani and Lucidi 2014, 35 .
} 
That hypothesis appears to become even more evident when moving from theoretical and empirical literature to specific case studies. To mention just one example, in a case study based on Lagos State, Nigeria, Afolabi concluded that "[judicial congestion] will directly affect the economy in a negative way by slowing down economic activities. Foreign investors who witness such a tortuous and long journey to justice may be discouraged from further investing $[\ldots]^{12}$ This is in line with the thinking of, for example, Schwartz, who argues that,

[W]hile it would be unusual for an investor to make an investment in a foreign country in the expectation that it will become the subject of a dispute, it would at the same time be rash to neglect the possibility that a dispute might occur; an investment will, at the end of the day, be only as secure as the processes that are available to deal with a related dispute, should one arise. ${ }^{13}$

Hence, dispute resolution, and in the current context, commercial dispute resolution in particular, appears to be highly relevant for unlocking economic potential. Improvement efforts to that respect can either address a whole country's existing judicial and dispute resolution framework, or to set up a separate 'off shore' solution, for example, a dispute resolution mechanism with limited mandate for a specific zone. In particular, the latter option has been used successfully for building investor confidence and economic development. As an example, the Dubai International Financial Centre (DIFC) has put Dubai on the map as one of the world's leading financial centres, categorized as a 'Global Leader' in the 2018 Global Financial Centres Index 24. ${ }^{14}$ Its legal autonomy, which includes its own judiciary via DIFC Courts, is considered a major factor of that success. ${ }^{15}$ As Amna Al Owais, Registrar of DIFC Courts, put it, 'In a world that is more globalized and connected than ever, one element still dictates the success of commerce-trust'.16 The chapter will look at the DIFC Courts as an example, under the heading 'Case Study: The Approach Implemented at the Dubai International Financial Centre' (Section 4).

\footnotetext{
12 Afolabi 2017.

13 Schwartz 2009, 128.

14 Yeandle and Wardle 2018, 17.

15 Strong and Himber 2009, 36-41.

16 Al Owais 2018, 1.
} 


\section{Making Judicial Reform Feasible: Commercial Dispute Resolution as Ideal Candidate for a Lighthouse Project}

Comprehensive judicial reform efforts have a reputation of being complicated and time consuming, with "the success of many court management and legal reforms [...] mixed". ${ }^{17}$ Without doubt, such reforms tend to be complicated, and involve a wide range of considerations as well as stakeholders in very sensitive areas. And they tend to be long-term processes. ${ }^{18}$ As Weisbrot lamented with respect to Australia, there are too many examples of reform promises that were "touted $[\ldots]$ as the solution to the problems in the court", only to find out that there are no quick fixes, easy options or panaceas..$^{19}$ Instead, a cautious balance of various factors and concerns is required. The integrity of justice is too high a value to make it the subject of hasty experiments. Therefore, this calls for in-depth structural reforms that aim to really identify and target the underlying root causes of challenges and reset the playing field for the coming years and decades in a comprehensive way.

At the same time, international (economic) competition and in many cases also the patience of a country's own citizens and the peculiarities of election cycles will not provide the time ideally needed for a comprehensive, in-depth effort without missing out on major opportunities that may otherwise translate into jobs, economic well-being, and stability.

Therefore, this chapters argues that judicial reform efforts are best carried out in a two-pronged way: (i) initiation of in-depth structural reforms where and as required, in (ii) parallel to focusing on selected initiatives with an immanent impact horizon, to build confidence quickly and create pilots for other (judicial) reform projects. In change management terms, such projects are often called lighthouse projects - a term that "refers to a model project that aims, besides its original purpose, to have a signal effect for numerous follow-up projects as they look towards it for inspiration and guidance". ${ }^{20} \mathrm{In}$ the specific judicial context, they provide the speed of results that is required for political reasons (as well as offering solutions to urgent challenges), but they are also enablers of in-depth structural reforms - by providing (initial) experiences and momentum for further efforts.

\footnotetext{
17 Hensler 2001, 4.

18 Legal Vice Presidency of the World Bank, 'Legal ad Judicial Reform' 2002, 11.

19 Weisbrot 2003, 243.

20 Wikipedia, 'Lighthouse Project'.
} 
A project can only serve as a lighthouse for others if it is actually delivered successfully. Sir Michael Barber, head of Prime Minister Tony Blair's Delivery Unit from 2001 until 2005, argued that the five key words of successful delivery are: ambition, focus, clarity, urgency, and irreversibility. ${ }^{21}$ Could a reform effort related to commercial dispute resolution serve as a lighthouse project for more in-depth structural judicial reforms, meeting the characteristics set out by Barber?

Improving commercial dispute resolution is certainly ambitious, given the complexities set out above-and at the same time it is not just a 'pet topic' but of immediate economic relevance. It can and should be treated as an enabler of economic development. It also allows to focus by narrowing in on a very specific area of dispute resolution, and in many cases an area which is characterized by a relatively small number of cases with relatively high individual values at dispute. The impact of smooth processes and state-of-the-art technology application can be felt very quickly in this area and it can be measured in terms of process quality (for example average resolution time, average time to first hearing, and similar metrics) as well as output quality (for example in terms of customer satisfaction surveys). It is also rather easy to communicate clearly why this particular reform matters, in terms of economic impact and hence job creation - and given the strong competition between countries, as argued above, the criterion of urgency is also met. Thus, irreversibility remains as a question mark. While one may remark that there is hardly anything that is truly irreversible, the example of DIFC Courts, to pick one, has demonstrated that by moving ahead ambitiously, new standards are set and quickly accepted and appreciated by investors, "who have flocked to the DIFC for peace of mind, offered by its common law framework and independent [...] judicial system". ${ }^{22}$

There are variations of the characteristics/criteria to be applied to define a lighthouse project. One variation of the same theme is to look at the five criteria of quick wins: no regret moves, high feasibility, relevance and ease of communicability. ${ }^{23}$ Again, it could be shown easily how commercial dispute resolution meets all of them.

Yet, while there is a strong case for commercial dispute resolution as a lighthouse for other judicial reform efforts, it doesn't mean that it is all simple and straightforward. A lot can be learned from existing experiences and

\footnotetext{
21 Barber 2007, 361.

22 Anderson 2017, 44.

23 As applied by Tony Blair Associates until 2017, and now by the Tony Blair Institute for Global Change, www.institute.global.
} 
benchmarks. There is no need to reinvent the wheel when it comes to developing effective (commercial) dispute resolution systems. Rather, it is important to learn from each other, to selectively consider international best practices and to benefit from successful expertise elsewhere.

\section{How to Do It: Bringing Together Multiple Factors}

This section examines how to transfer theory into practice, by (i) retaining customer centricity as the guiding principle to developing effective (commercial) dispute resolution systems and (ii) using five building block in the process.

\subsection{The Guiding Principle: Customer Centricity}

The key to success is to take a step back and look at (commercial) dispute resolution in a somewhat more abstract way: At the end of the day, despite all the specificities of a judicial system and the special considerations and sensitivities, we are talking about delivering a service to customers that those customers are paying for. Switching from 'party' to 'customer' in itself already constitutes a very significant shift, not just in terminology, but very much in the underlying thinking.

Those customers are expecting a good overall experience. It is the nature of dispute resolution that very often, there is a winner and a loser. However, even the loser of a specific case should be content with the process. The Australian Law Reform Commission pointed out in 2000 that international research makes plain that "parties can and do distinguish between their relative happiness with the result, and their satisfactions with the process". ${ }^{24}$

So, when embarking on achieving dispute resolution excellence, the core question is very similar to the one any entity providing customer services should focus on: how to achieve a good customer experience? And the answer is not so dissimilar either: by customer needs focused rules, by processes that put customers into the centre of attention and consideration, by having good staff and then developing them further in proper and adequate ways, and by 'marketing' the services and solutions offered. Last, but not least, anyone who has ever attempted to introduce new offerings will bear testimony that this requires a proper strategy bringing all the elements together, as well as implementation discipline and coordination (or, in other words, proper change management). 


\subsection{The Five Building Blocks}

In 2000, the Australian Law Reform Commission published a major report reviewing the federal civil justice system of Australia. ${ }^{25}$ Reviewing and commenting on those findings of the Australian Law Reform Commission, Weisbrot emphasized that "justice systems are large, complex, organic creatures. Effective reform, therefore, requires a holistic approach, and a collaborative effort from all of those actors and stakeholders involved". ${ }^{26}$ Looking at case studies of judicial reform in Central, Eastern, and Southeastern Europe ${ }^{27}$ as well as from elsewhere around the world, ${ }^{28}$ the requirement of a holistic approach is not just confirmed but actually strengthened.

For such a holistic approach, it would be a mistake to focus just on formal rules and the processes. ${ }^{29}$ The need for ensuring excellence of people and of investing into their continuous skill building as well as for clear positioning, outreach and reputation building, or in other words, good communications, are just as relevant. ${ }^{30}$ When bringing those elements together and combining them with the requirement of a clear overall strategy with strong change management in place, five building blocks can be depicted as in Figure 12.1: ${ }^{31}$

The following paragraphs set out further detail about such five building blocks, taking them in turn, as follows.

Legal basis: Ensuring the laws and supporting decrees or guidelines are in line with best practices and allow for the desired changes is a critical starting point. Nothing that is planned must contravene against the governing legal foundations; all legal safeguards must be duly respected. At the same time, there is a tendency in judicial reforms to immediately focus on adjusting the legal framework, rather than exploring first what is feasible within it.

Organisational and physical setup: Advice for creating or amending the legal basis might be very important - but if a reform stops there, it is bound to fall short of its own objectives. It is in the space of the organizational and physical setup, which also includes the (re-)design of all processes and the supporting technological infrastructure, that in many cases, most impact can be achieved.

People excellence and skill building: The best legal basis and the best processes (in theory) are of no use if the people involved do not meet the quality standards expected of them. It is no surprise that over the last years, a 'market'

\footnotetext{
25 Australian Law Reform Commission 2000.

26 Weisbrot 2003, 250.

27 IMF 2017, 39-96.

28 Legal Vice Presidency of the World Bank, 'Legal and Judicial Reform' 2002.

29 Weisbrot 2003, 250.

30 Anderson 2017, 46.

31 The Metis Institute, 'How We Can Help'.
} 


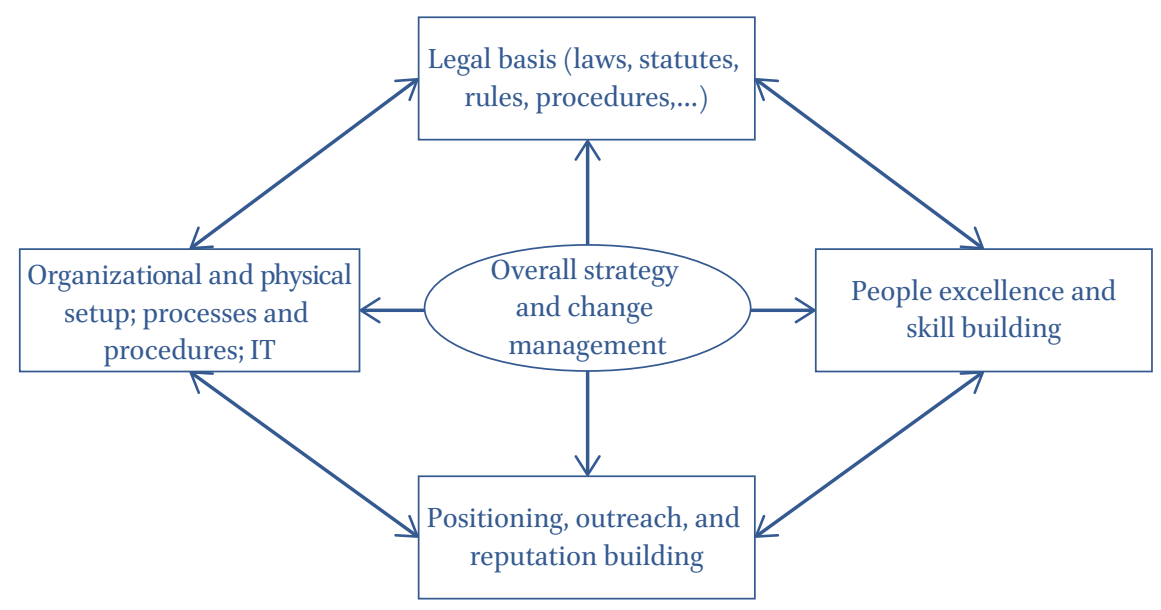

FIGURE $12.1 \quad$ The Five Building Blocks

for highly respected retired judges from countries such as the United Kingdom has evolved among more newly set up commercial dispute resolution players - it is a way of achieving and demonstrating a commitment to high standards as well as sending a signal about seriousness with respect to independence and integrity. ${ }^{32}$ However, people excellence should not be restricted to the most senior roles - rather, it needs to be a theme through all ranks, all the way to the most junior roles. In this context, systematic skill building (not only to strengthen classical judicial expertise, but also with a focus on topics such as customer service) achieves significant improvement results.

Positioning, outreach, and reputation building: Strategic communications in all its aspects is an integral element of successful rule of law/commercial dispute resolution projects. Good substance and strong communications are mutually dependent and reinforcing. Internal stakeholders need to know about innovations and embrace them. External stakeholders, in the legal community and the wider public, need to be aware and become supportive of changes - and of the offering after changes.

Overall strategy and change management: Each and every component mentioned above is important - but if they don't come together in a coordinated way, success will be very difficult to achieve. As with any other major reform

32 For example, DIFC Courts (Dubai, UAE), ADGm Courts (Abu Dhabi, UAE), Qatar International Court and Dispute Resolution Centre (Doha, Qatar) and AIFC Courts (Astana, Kazakhstan) all rely on experienced judges from common law jurisdictions among their judges. 
effort, a clear overall strategy and a systematic change management that keeps track of progress, intervenes where required but also motivates and rewards is quintessential.

Case Study: The Approach Implemented at the Dubai International Financial Centre

The following section provides a snapshot of how commercial dispute resolution is set up at the Dubai International Financial Centre (DIFC), United Arab Emirates, and showcases some reasons for its success, for illustration purposes. It is not a solution that can be simply copied to other situations, as any solution needs to be custom-tailored to the specific context to be in line with constitutional as well as political and economic requirements. That said, it provides examples and food for thought. ${ }^{33}$

Over the course of the last decade, commercial dispute resolution at DIFC has become an outstanding example of how to achieve excellence in dispute resolution in a modern, innovative, and business-friendly way. It has proven that it is possible to set up a dispute resolution ecosystem in a fair, transparent, timely as well as cost-effective manner, using the latest technologies.

The DIFC Courts are complemented by the DIFC Arbitration Institute, the Academy of Law, and the DIFC Wills and Probate Registry, all under the umbrella of the DIFC Dispute Resolution Authority. ${ }^{34}$

The DIFC Courts started hearing cases in 2008, with the clear and explicit objective of increasing the attractiveness of the Dubai International Financial Centre and helping solve civil and commercial disputes. Over the course of the last decade, the DIFC Courts have become part of the world's leading commercial courts, with jurisdiction to hear cases from around the world, at the forefront of latest technology and with a continuous drive to innovate further.

Its relentless customer orientation, along with the use of the latest technologies and a business-friendly set of rules have made all the difference. Key characteristics of the DIFC Courts include flexible resolution paths (including a small claims tribunal, which has become very popular as it offers an accelerated case handling path at lower cost), 24/7 urgent application facilities, remote secure on-line case progression systems and, in the particular case of Dubai, the advantage of operating under common law and using the English language.

33 The status described below is accurate as of o1 February 2019.

34 See www.dra.ae, accurate as of o1 February 2019 
While this DIFC model is not a blueprint for every situation, many of its characteristics are a very good starting point. Indeed, they have been copied and used in that way in multiple geographies, and have thereby benefitted other countries around the world, both civil and common law jurisdictions alike.

Even the most excellent benchmarks of today will be outdated and fall behind in the future unless pursuing a continuous and relentless strive for innovation. And in today's world of ever accelerating technological advance and ever new ways of interacting and communicating at global scale, falling behind might be a matter of months or maybe a year or two, but certainly not of a decade or two.

While there isn't the magic crystal ball to forecast the future of commercial dispute resolution, there are a few trends that are already visible and that are fundamentally reshaping how to think about the matter and therefore set up for commercial dispute resolution excellence. This section looks at four hypotheses as food for thought. They do not meet the intellectual quality criterion of being 'MECE' (mutually exclusive, collectively exhaustive), as they are not necessarily mutually exclusive and are not even trying to claim to be collectively exhaustive. However, they are substantial considerations

\subsection{Hypothesis One-Courts of the Future will be a Virtual Service Rather than a Physical Location}

The premise: commercial dispute resolution is a paid-for offering. 'Courts of the Future' will be a service rather than a location, with courtrooms of the future being virtual and customer centric providers capturing the market.

Already above, the case was made that commercial dispute resolution should be looked at as a customer needs' focused service. This has a whole range of implications on the type of services offered, and the quality standards to strive for. In many cases, it is also a challenge in terms of changing the mindsets of many of the actors involved. Yet, of the many (and often impressive) initiatives underway in this area, practically all are looking into how to optimize an offering that is still focused around specific physical locations. Basically, we are looking at an optimization within the frame of a current set of assumptions that are often not challenged.

However, at the same time, more and more business is done in the virtual space - and this is where dispute resolution needs to follow, to meet the needs and expectations of its customers. In a first step, the focus is on making 
services location independent but still location focused. In other words, the dispute resolution services are still provided at/from a specific location, but it is not required anymore for the parties (or better, customers) to physically come to that location.

Initially, this included options such as remote filing (for example, via fax), then secure online filing and exchange of documents. Increasingly, video conferencing is incorporated into procedural rules and actual practice where and as required and is used to accelerate and simplify trials. At some courts, such as the DIFC Courts in Dubai, small claims tribunals were actually designed in a way that considers remote access (including via mobile phones) the default option-and parties coming into a court room the exception. This has had significant impact on the design of the processes, and there were a number of legal concerns that had to be discussed and addressed. But feedback as well as acceptance demonstrate that, once initial scepticism had been overcome, this was the right path to take.

One step further, 'remote courts' are increasingly under discussion, including such countries in Africa that are struggling with relatively long distances that are often very burdensome to travel. The underlying idea is simple. Physical court facilities with proper benches of well trained (in this case, commercial) judges are set up in one or a few of the major urban centres of the country. Typically, existing facilities are used. Even though they may need to undergo some adaptations, that helps to manage cost. Those facilities are referred to as 'hubs'. They are equipped with conference room like court rooms that are optimized for video-conferencing. The video-conferencing equipment allows to connect to 'spokes' all over the country. The spokes equipment is typically placed in a room, for example, at a local police station or district/city officeor even at health stations or religious facilities. It is handled by a local clerk who is technically trained and also authorized to verify identities on behalf of the judiciary. That judicial role is only a part-time one for most clerks, unless the caseload and activity levels at a specific location justify a full-time position. The parties come to a local spoke (or can also come to two different ones if this is more convenient for them), and at a predetermined time, they are linked to the judge(s) assigned to hear their case-with the judge physically at the hub location. Such a set-up exhibits as series of advantages:

- This provides access to specialized, well qualified judges even in more remote areas.

- It reduces the cost and improves the efficiency of providing such judicial services, even compared to a 'travelling judges' models.

- It allows to balance case load across the whole country or within regions of a country, assigning centralized resources as required. 
Actually, from a technology perspective there is not even a real need for having physical locations for the spokes at all. Basically, each and every smartphone with a camera (in other words, pretty much any phone in the meantime) can become a spoke. And the judges can log in from pretty much any location as well. Yet, for the time being, there are understandable concerns about going totally remote. Compromises between what is technologically feasible (and potentially effective as well as efficient) and what is culturally acceptable (at least initially) and reflected in laws and regulations may actually be the price to pay for advancing. But the trend is very obvious. And this is just one specific example of what is already happening - it doesn't take much fantasy to imagine how to advance this further and/or apply it to areas of dispute resolution other than commercial dispute resolution.

The next logical step may well come out of the gaming industry. Already, ${ }_{3} \mathrm{D}$ avatars are created and used. There are a number of solutions at various stages of testing that allow to basically scan a human to create an advanced ${ }_{3} \mathrm{D}$ avatar, and then - with the help of sensors and cameras - capture every move of that individual and reflect it onto the $3 \mathrm{D}$ avatar. And that technology is advancing quickly, capturing ever finer distinctions (for example, changing facial expressions), while at the same time becoming cheaper and easier to handle in terms of equipment required. We are not fully there yet, but just imagine for a moment a 'virtual courtroom' that is populated by realistic $3 \mathrm{D}$ avatars of the judge(s), the parties, their lawyers, and other court personnel. All those avatars connect to their respective 'owners' in real-time, reflect their emotions, their body language, their facial expressions. One of the key concerns regarding video-conferencing is that a lot of non-verbal communication may be lost. Well, that problem will be overcome.

But it is not just about the hearings that may eventually move fully into virtual spaces. Blockchain is already changing how business is done in certain sectors, and how contracts are handled. It has the potential of changing the way (commercial) disputes are processed-and judgements enforced-in a very fundamental way.

So, we may not know exactly what the future will look like, but from the above examples, it does sound like a reasonable hypothesis to say: the 'Courts of the Future' will be a service rather than a location. In the words of Amna Al Owais, Registrar of DIFC Courts at a conference in January 2018, "Perceptions need to change from the Courts as a concrete building to a trust-worthy service provider". ${ }^{35}$ 


\subsection{Hypothesis Two-Increasing Differentiation and Competition}

The premise: commercial dispute resolution will become far more differentiated, as well as competitive on the international stage.

At the beginning of this section, the caveat was raised that the four hypotheses may not be mutually exclusive (and certainly not collectively exhaustive). This second hypothesis is an example of that, as it is closely linked to the first one discussed above. In a world where Courts of the Future are a service rather than a location, physical proximity becomes less and less relevant. Geographic distance is not a real barrier or even burden anymore. As a consequence, parties will have much more choice.

Already today, for large contracts, arbitration clauses typically stipulate fora that are acceptable to both parties but might actually be at quite a distance from the physical location of either of them. If a lot of money is at stake, the cost for travel and accommodation might look acceptable. But it does not work for smaller disputes. Yet in a world with more virtual or at least remote offerings (and hence less need to travel physically), a wider set of dispute resolution providers and options suddenly opens up to parties even of smaller contracts/ disputes.

For the dispute resolution providers, this means increasing opportunities but also competition across national boundaries-especially if global enforceability continues to become simpler and more feasible. Blockchain, already mentioned above, might have an important role to play in that enforcement context, at least for commercial cases.

Once again looking at 'normal businesses' and drawing comparisons from there (even though this is often frowned upon in the judicial/dispute resolution context), increased competition puts urgency to the need of differentiation from others, in order to succeed-customers can't be taken for granted anymore. Multiple paths exist to achieve that differentiation-and will most likely be combined by providers in one way or another, such as the following: - The path of outstanding rules: Of course, all judicial or alternative dispute resolution providers (at least those playing in the upper tier) will claim that their respective rules and regulations are 'state of the art' and 'catering to business needs'. And to a certain extent, that is true-comparing the rules of leading arbitration centres, as an example, one finds a variety of differences in details but overall, there are remarkable similarities. Hence, excellent rules are a must and critical, but hardly the major sustainable differentiation factor.

- The path of judicial excellence: At the end of the day, the quality of the judges, arbitrators or mediators will make a major difference to parties. Hence, we are likely to see an increasingly international competition for outstanding judges/arbitrator, especially such that are trained in common law. The 
profession of judges, which always used to be an example of a very domestic role, is becoming part of an increasingly global labour market, at least at the top end of commercial dispute resolution.

- The path of specialization: Marine tribunals, construction tribunals, special banking tribunals (including for specific sub-sectors of the financial industry), other business sector specific tribunals, specific goods focused tribunals - there is no limit to the ideas of what to create special tribunals for. This should offer providers an opportunity to stand out from the general field; and it allows parties to select a tribunal that truly understands their industry and that they feel comfortable with.

- The path of five-star excellence: Service quality and customer experience are areas that allow providers to differentiate themselves in a way that complements judicial quality. This includes online offerings, opening times, customer service response times, feedback loops in case of (non-judicial) issues but also the look-and-feel of any physical facilities, to mention a few examples.

- The commodity path: Looking at retail shops, it is not all high-end boutiques with very sophisticated interior design, highly qualified shopping assistants and complimentary coffee offered all the time. There is a very significant role for discount markets that are often stripped down to the bare bones and rely on self-service with rather little support. Why do people go there? Because it is way more affordable. Linking this to the topic of commercial dispute resolution: very likely, there is a market for cheaper, reduced services offerings. Bringing back the example of DIFC Courts, a small claims tribunal is already offered that provides a slimmed down version at lower fee levels (even though still at a very high-quality level). It has proven very successful. Which path(s) will be the most successful? This remains to be seen. The best guess is that there will be a range of models, catering to different clienteles and needs. However, all of that supports the hypothesis: Commercial dispute resolution will become far more differentiated, as well as competitive on the international stage.

\subsection{Hypothesis Three-Strong Role of Private Offerings}

The premise: private sector solutions will complement and compete with state-offered or endorsed solutions.

The increasing importance of private sector solutions is already evident, as can be seen by the fast growth of alternative dispute resolution offerings. (Semi-)Private providers are offering an increasing number of alternatives to state-run judicial offerings. This is a trend that is likely to continue. For public sector providers (judiciaries), this has already triggered the need for a very important debate. What should be the relationship between judiciaries and 
private sector offerings? Initially, many-chronically under-resourcedjudiciaries are simply glad about any reduction of case load.

But then, the discussions start. Should the judiciaries actually take up the challenge and 'compete' pro-actively? Or should they just 'lean back'? Is there a certain 'supervisory' responsibility? When should there be intervention by state authorities? If the hypothesis of private sector offerings gaining more and more importance is correct, those are discussions that will become even more relevant—and potentially controversial—over the coming years.

\subsection{Hypothesis Four-Artificial Intelligence as a Fundamental Game Changer}

The premise: artificial intelligence is about to change the face and nature of dispute resolution fundamentally.

Let's think about judicial dispute resolution in a slightly more abstract way. What is it, at the end of the day? A submission by a party basically constitutes 'fuzzy information'. The same could be said of witness statements and so on. The judge's role is to structure that fuzzy information, recognize patterns, distil the essence and then-in a common law context-search for relevant precedence. In a civil law context, he/she searches for relevant statutes-and de facto once again looks for indicative precedence (even if it is not binding in the common law sense). The results of that search are then applied to the facts of the specific case, for determining judgement.

Formulated slightly different: Fuzzy information is processed to recognize patterns (as well as contradictions) and then compared against a database of earlier-generated information, which leads to a (hopefully) logical resultwhich in turn feeds into the database, for future use. Put into that kind of wording, it starts sounding like a classical application field for artificial intelligence.

And actually, why should the (commercial) dispute resolution space be the one area that is not fundamentally changed by the new possibilities offered by using artificial intelligence? It might sound utopian, but in the following paragraphs, a future scenario is painted that is probably not even that far out anymore.

Whenever a party or its representatives file a case and once the response of the other side and the necessary evidence are captured, an artificial intelligence-based application assesses, based on the data it has access to, whether it can 'solve' that case itself, without human decision maker involvement. Only the few cases that are likely to require true human creativeness are flagged and routed toward a special path. The majority of cases reach draft decision stage literally within minutes, if not seconds, after receiving the necessary pieces of input information-all automatically, 24/7,365 days a year. This could be 
offered at highly competitive cost. If a party feels that 'the machine' has treated it unfairly, it may have a right of 'rejection' (in a simpler way than having to file an appeal). In case of rejection, the case is reviewed by a judge in the traditional way (one can discuss whether with or without knowledge of what the machine suggested); if the judge comes to the same conclusion as the artificial intelligence application, that could have cost implications for the party that rejected-in order to discourage automatic rejection. If no rejection is filed, for example, within two weeks say, the draft generated by artificial intelligence becomes a binding and fully enforceable judgement. The advantage of such a-currently still somewhat hypothetical — scenario: that a large number of cases that clog dispute resolution providers (especially judiciaries) are rather standardized, so if one could get rid of a significant share of them, as far as the need for allocation of human resources is concerned, this would free up the capacity of judges to focus on the truly complex cases that require creative consideration.

Let us take that intellectual experiment (which is actually not so far from the reality of the relatively near future as it may sound) one step further: Whoever programs the algorithms of the underlying system and owns the rights to it, has a very valuable — and also sensitive - instrument at his or her hands. Leave aside all the considerations from a manipulation risk and security perspective for a moment-even though they will need to be taken very seriously and dealt with accordingly. Just think of the commercial value of such a product: if the same company that provides the system to a judiciary (maybe at very attractive commercial terms) also creates a commercial version that is available to, for example, law firms (at commercial terms that are probably very attractive to the offering company), law firms will have little choice other than to get that software-after all, they would want to understand what the automated system is likely to generate based on the input of themselves and likely inputs by the other party, witnesses, and so on.

This may sound scary. Yet, before everyone starts shouting out in panic about such a scenario, think about it in abstract. Buying such software is just the modern-day version of what legal practitioners have actually done for centuries. They have purchased access to information helping them do their jobs in the best interests of their clients. For a very long period, the carriers of such information were books, hand-written or then printed. A few decades ago, online decision search databases started emerging, and having access to them quickly moved from being a nice-to-have luxury to a necessity even for the most junior associates in law firms. Decision simulation software, based on similar data and algorithms that the judiciary is also using, may just be the logical next evolution—and one could even argue that this will help avoid 
unnecessary cases (or encourage settlement), as parties may get an earlier glance at where their cases are heading.

So, no doubt, artificial intelligence is about to change the face and nature of (commercial) dispute resolution fundamentally. This will raise a number of valid concerns that will need to be taken very seriously and considered appropriately_yet it is about to open a lot of upside as well.

Is such futurology a mere provocation or a realistic scenario? Some readers might find the above a bit too fantastic and/or provocative. Well, such scenarios have been painted not to say that this is exactly how the future will look like, but to make abstract statements regarding the emerging importance of artificial intelligence more tangible and to provide food for thought and discussion.

We are heading into times of exciting changes and opportunities, also in the space of (commercial) dispute resolution. This will allow access to high quality dispute resolution at a level of effectiveness and efficiency that we have not yet seen; and that's excellent news for economic activities and development. Yet it will also throw up ethical and regulatory questions that haven't been relevant so far. And just think beyond the realm of commercial dispute resolution for a minute-for example to criminal justice. This raises an even wider set of questions (for example 'sentencing by computers' - is that actually fairer or a violation of human rights?).

So, to bring it back to the core of this chapter, it started by arguing that commercial dispute resolution has a significant impact on economic opportunities and development. It then demonstrated that a lot can be learned from experiences globally, and that commercial dispute resolution actually meets all the requirements for good lighthouse projects. Then, this section has taken it one step further, pointing out that - beyond implementing current best practicecontinuous innovation will be required to cope with and actually take advantage of the rapidly evolving context. If done well, significant impact can be achieved.

The Role of International Organizations in Strengthening Commercial Dispute Resolution

International organizations can play a major role as enabler, facilitator and potentially catalyst in efforts to strengthen commercial dispute resolution. A first role could be seen as simply providing opportunities, such as conferences, for the exchange of ideas and for discussions that will advance this field. Beyond this rather general and generic aspect, there are three very specific roles 
for international organizations, and for international development banks in particular:

- They could use their leverage to encourage countries or other regional partners to invest into commercial dispute resolution. By stipulating improvements in (commercial) dispute resolution offerings as one of the accompanying conditions of certain financing mechanisms (whether more or less formally), international actors can create some very strong and attractive incentives that will make a real difference.

- They could support efforts in those areas directly, for example via technical cooperation/assistance arrangements. Many international actors have technical assistance programmes or support of one or the other nature. Strengthening the rule of law is actually often included as one of the key objectives of such programmes. However, so far, commercial dispute resolution is somewhat overlooked as an opportunity for achieving significant impact in a rather short period of time, with very reasonable resource requirements.

- They could reward successful efforts via future project evaluations and/or by actually using those fora themselves for resolving disputes they are involved in. At the end of the day, the ultimate 'stamp of approval' and sign of trust is to use a specific dispute resolution offering for one's own purposesor to otherwise attach direct positive effects.

Each of those (potential) roles warrants further considerations that would exceed the scope of this article but are certainly worth thinking about.

Effective and efficient commercial dispute resolution (and enforcement) is a powerful yet often overlooked driver of economic attractiveness of countries and of specific (free) zones. Success cases such as at the Dubai International Financial Centre, UAE, have demonstrated the difference state-of-the-art dispute resolution makes to investors - and the feasibility of it. The key is to focus not just on legal drafting, but to combine that with a strong process (and technology) focus, dedicated skill building efforts and systematic communications. At the same time, a number of trends are going to fundamentally change the face and approach of commercial dispute resolution, towards a more differentiated, customer-centric offering that will benefit from technological advances. Those advances will also raise a whole new set of ethical and regulatory challenges. International organizations, and multilateral development banks, can act as initiators and/or facilitators of discussions, support efforts 
via technical cooperation/assistance arrangements, and actually benefit themselves from improved, more differentiated dispute resolution offerings.

\section{Reference list}

Afolabi T, 'Promoting Dispute Resolution and Economic Growth. Nigerian Institute of Chartered Arbitrators Online Papers' (2017), <https://nicarb.org/2017/06/29/ promoting-dispute-resolution-and-economic-growth-paper-presented-by-barr-drtaiwo-olayinka-afolabi-mon-fcarb/>

Al Owais A, 'Speaking Notes-Global and Local Challenges in Commercial Dispute Resolution' (Fourth International Conference on Emerging Research Paradigms in Business and Social Sciences, Dubai, January 2018) <www.difccourts.ae/2018/01/25/ global-and-local-challenges-in-commercial-dispute-resolution/> accessed 19 February 2019.

Anderson R, 'Bringing the DIFC Model to the World' [2017] Gulf Business 44.

Australian Law Reform Commission, Managing Justice: A Review of the Federal Civil Justice System (ALRC Report 89, 2000).

Barber M, Instruction to Deliver-Tony Blair, Public Services and the Challenge of Achieving Targets (Politico's Publishing 2007).

Barros P and Cabral L, 'Competing for Foreign Direct Investment' (2000) 8 Review of International Economics 360.

Bellani M, Judicial Efficiency and Foreign Direct Investments: Evidence from OECD Countries' (2014) European Trade Study Group Paper 358 <www.etsg.org/ETSG2014/ Papers/358.pdf $>$ accessed 19 February 2019.

Cross F B, 'What We Know and Do Not Know about the Impact of Civil Justice on the American Economy and Polity' (2002) 8o Texas Law Review 1737.

Fry J, 'Arbitration and Promotion of Economic Growth and Investment' (2011) 13 European Journal of Law Reform 388 .

Gonzalez A, 'Global Investment Competitiveness: New Insights on FDI' (26 October 2017) <https://blogs.worldbank.org/psd/global-investment-competitiveness-newinsights-FDI> accessed 19 February 2019.

Hensler D, 'The Contribution of Judicial Reform to the Rule of Law' (the Conference on New Approaches for Meeting the Demand for Justice, Mexico City, May 2001) $<$ https://siteresources.worldbank.org/INTLAWJUSTINST/Resources/hensler speech.pdf $>$ accessed 19 February 2019.

Hornberger K, Battat J and Kusek P, 'Attracting FDI: How Much Does Investment Climate Matter?' (ViewPoint: Public Policy for the Private Sector, August 2011) <https:// openknowledge.worldbank.org/handle/10986/1106o> accessed 19 February 2019. 
International Monetary Fund, Europe Regional Economic Outlook: Europe Hitting Its Stride' (IMF 2017) <https://www.imf.org/en/Publications/REO/EU/Issues/ 2017/11/06/Eurreo1117> accessed 19 February 2019.

Lorenzani D and Lucidi F, 'The Economic Impact of Civil Justice Reforms' (2014) European Commission Economic Papers $530<$ http://ec.europa.eu/economy_finance/ publications/economic_paper/2014/pdf/ecp530_en.pdf > accessed 19 February 2019. McConnaughy P, 'The Role of Arbitration in Economic Development and the Creation of Transnational Legal Principles' (2013) 1 Peking University Transnational Law Review 10.

Schwartz E, 'The Role of International Arbitration in Economic Development' (2009) 12 International Trade and Business Law Review 127.

Strong M J and Himber R, 'The Legal Autonomy of the Dubai International Financial Centre: A Scalable Strategy for Global Free-Market Reforms' (2009) 29 Economic Affairs 36 .

Legal and Judicial Reform Practice Group of Legal Vice Presidency, 'Initiatives in Legal and Judicial Reform' (The World Bank 2002) <http://siteresources.world bank.org/BRAZILINPOREXTN/Resources/3817166-1185895645304/40441681186409169154/18initiativesFinal.pdf> accessed 19 February 2019.

The Metis Institute, 'How We Can Help' (The Metis Institute) < www.themetisinstitute. org/how-we-can-help> accessed 20 February 2019.

The World Bank, 'Enhancing Contracts Methodology' (The World Bank) <www.doing business.org/en/methodology/enforcing-contracts> accessed 20 February 2019.

Vuksic G, 'Developing Countries in Competition for Foreign Director Investment' (2015) Economics Paper $3508<$ https://wiiw.ac.at/developing-countries-incompetition-for-foreign-direct-investment-dlp-3508.pdf $>$ accessed 19 February 2019 .

Weisbrot D, 'Reform of the Civil Justice System and Economic Growth: Australian Experience' (2003) 6 Flinders Journal of Law Reform 235.

Wikipedia, 'Lighthouse Project' (Wikipedia) <http://en.wikipedia.org/wiki/Light house_Project $>$ accessed 20 February 2019.

Yeandle M and Wardle M, The Global Financial Centres Index (24th edn, the China Development Institute \& Z/Yen Partners 2018) <www.longfinance.net/media/ documents/GFCI_24_final_Report.pdf $>$ accessed 19 February 2019 . 